\title{
The protective effect of Phellinus linteus decoction on podocyte injury in the kidney of FSGS rats
}

\author{
Feng Wan ${ }^{1}$, Ru-chun Yang ${ }^{1 *}$, Yan-peng Shi', Yue-Wen Tang ${ }^{1}$, Xuan-li Tang ${ }^{1}$, Xiao-ling Zhu' ${ }^{1}$, You-gui Li ${ }^{2}$ and
} Yong-jun Wang ${ }^{1}$

\begin{abstract}
Background: This study aimed to investigate the effect of the Phellinus linteus (Mesima) decoction on podocyte injury in a rat model of focal and segmental glomerulosclerosis (FSGS) and evaluate the potential mechanisms.

Methods: FSGS resembling primary FSGS in humans was established in rats by uninephrectomy and the repeated injection of doxorubicin. The FSGS rats were randomly divided into the model group, low-dose group of $P$. linteus decoction (PLD-LD), medium-dose group of $P$. linteus decoction (PLD-MD), and high-dose group of $P$. linteus decoction (PLD-HD). Blood and urine analysis were performed after 12 weeks and the molecular indicators of renal function and the renal pathological changes were examined.

Results: FSGS developed within 12 weeks in the test group and showed progressive proteinuria and segmental glomerular scarring. Urinary protein, serum creatinine, urea nitrogen, triglycerides and cholesterol were significantly reduced following the 12-week intervention with P.linteus decoction, especially in the PLD-LD group. Renal nephrin and podocin were markedly increased. Moreover, the pathological damage in the renal tissue was alleviated by the PLD-LD intervention.
\end{abstract}

Conclusion: The P. linteus decoction alleviated the podocyte injury in the FSGS rat model, thus minimizing the progression of glomerular sclerosis and improving renal function.

Keywords: Phellinus linteus decoction, Protective effect, Podocyte injury, FSGS, Rat

\section{Background}

Focal and segmental glomerulosclerosis (FSGS) represents a frequently occuring glomerular kidney disease [1]. It is usually delineated as a clinical-pathologic syndrome manifesting proteinuria, and focal and segmental glomerular sclerosis with foot process effacement [2]. The main clinical manifestation of FSGS is proteinuria. Currently, the first-line of treatment in idiopathic FSGS with nephritic syndrome is a prolonged course of corticosteroids [3]. Unfortunately, the occurrence of steroid resistance or steroid dependence is commonly reported. FSGS may still result in end-stage renal failure despite

\footnotetext{
*Correspondence: yangruchunhz@163.com

'Department of Nephrology (Key laboratory of Zhejiang province,

management of kidney disease), Guang Xing Hospital Affiliated to Zhejiang

Chinese Medical University, Hangzhou 310007Tiyuchang Road 453People's

Republic of China

Full list of author information is available at the end of the article
}

intensified immunosuppressive therapy. Thus, it remains an enormous challenge to find novel and effective treatments for FSGS.

Traditional Chinese medicines have been considered as effective treatments for a variety of different physical conditions, including renal diseases [4]. Phellinus linteus (Mesima), a kind of mushroom that grows mainly on wild mulberry tree trunks, is used extensively as a traditional medicine in China, Korea, Japan, and other Asian countries for the treatment of different diseases [5]. The main biological functions of $P$. linteus include anti-cancer, antioxidant, anti-inflammatory, hypoglycaemic and anti-fibrotic [6-10]. Considering its remarkable anti-cancer effects, $P$. linteus has become a research hotspot at home and abroad. However, its application in the treatment of kidney diseases at home and abroad is scarce.

(c) The Author(s). 2019 Open Access This article is distributed under the terms of the Creative Commons Attribution 4.0 International License (http://creativecommons.org/licenses/by/4.0/), which permits unrestricted use, distribution, and reproduction in any medium, provided you give appropriate credit to the original author(s) and the source, provide a link to the Creative Commons license, and indicate if changes were made. The Creative Commons Public Domain Dedication waiver (http://creativecommons.org/publicdomain/zero/1.0/) applies to the data made available in this article, unless otherwise stated. 
As is known, many pathological factors played important roles during the occurrence and progression of kidney disease, including oxidative stress, inflammatory reaction, immune disorder, and disturbances of glucose and lipid metabolism. These coincide with the multifaceted pharmacological effects of $P$. linteus mentioned above, which make us postulate that $P$. linteus may have protective effect on the kidney. Expectedly, in our previous study, we found different extracts from $P$. linteus can inhibit TGF- $\beta 1$-induced epithelial-mesenchymal transition in renal tubular epithelial cells (NRK-52E) [11]. Additionally, it is worth noting that a recent literature showed that polysaccharides from $P$. linteus can reduce renal interstitial fibrosis in diabetic nephropathy mice [12]. These indicated $P$. linteus had great potential in preventing and protecting kidney disease. However, further validation is still needed.

In this current study, we established a FSGS rat model through uninephrectomy and repeated doxorubicin administration. Next, we evaluated the potential therapeutic effects of $P$. linteus on the FSGS rat. We assessed the urinary protein levels, kidney function, expression of podocyte slit diaphragm proteins (nephrin and podocin), and the pathomorphology of the FSGS kidney tissues in the different treatment groups of rats. Our results elucidated the potential therapeutic value of $P$. linteus in the treatment of FSGS.

\section{Methods}

\section{Preparation of $P$. linteus decoction}

The powder of $P$. linteus (Mesima) was prepared and provided by professor You-gui Li, Zhejiang Academy of Agricultural Science. The $P$. linteus used in this study was authenticated by the Institute of Microbiology of Chinese Academy of Sciences. The specimen of $P$. linteus has been kept at the herbarium of Zhejiang Academy of Agricultural Science.

According to the ancient books (Sheng ji zong lu and $\mathrm{Pu}$ ji Fang), the recommended clinical dosage of P. linteus is about $10 \mathrm{~g} / \mathrm{d}$ for adults. The appropriate dosage for each rat is calculated on the basis of body surface area [13]. In our experiment, in combination with some preliminary experiments, we finally chose the dosage of PLD-LD, PLD-MD, and PLD-HD is $4 \mathrm{~g} / \mathrm{d}, 8 \mathrm{~g} / \mathrm{d}$, and $16 \mathrm{~g} / \mathrm{d}$, respectively. The decoction was prepared as follows: the powder was initially soaked in distilled water for half an hour, and then decocted for $30 \mathrm{~min}$ two times, in accordance with conventional method. Finally, the decoctions were combined and filtered using a double-layer gauze, and concentrated to the required volume for spare.

\section{Experimental animals}

Clean-grade male Sprague Dawley rats $(n=30)$ weighing $160-180 \mathrm{~g}$ were purchased from the Zhejiang Institute of Traditional Chinese Medicine (animal qualification certificate number: SCXK [shanghai] 2013-0016). The rats were housed under standard conditions and the experiments were performed in accordance with the local guidelines of animal experiment center, for the care of laboratory animals. All animal experiments were approved by the ethics committee for research on laboratory animal use of the Zhejiang Institute of Traditional Chinese Medicine (Tianmushan Road No.132).

\section{Study of $P$. linteus in FSGS rats}

The rats were allowed to acclimatize for a week prior to stating the experiments, and then weighed and numbered according to their body weight (from light to heavy). At first, six rats were randomly selected as the control group by the random number table. The remaining 24 rats were used to establish the FSGS model ( $n=6$ rats/group). Based on the proteinuria difference between the control and model group in our preliminary experimental results, the total rat numbers in our study were determined. Thereafter, the FSGS rat model was established as previously described $[4,13,14]$. Briefly, the rats were firstly subjected to uninephrectomy (left side) on day 1 , followed by the administration of doxorubicin through caudal vein, $5 \mathrm{mg} / \mathrm{kg}$ (on day 7) and $3 \mathrm{mg} / \mathrm{kg}$ (on day 28), respectively. For the control rats, they were correspondingly injected equivalent saline on day 7 and day 28 following the sham operation.

The FSGS rats were allocated randomly to four groups: model group, PLD-LD, PLD-MD, and PLD-HD ( $n=6 /$ each group). The intervention with different concentrations of $P$. linteus decoction by gavage was initiated on day 2. After administration for eight consecutive weeks, the serum and whole right kidneys were harvested for biochemical, histological, and molecular analyses, and followed by the euthanisation of the animals by dislocation of the cervical spine. Urine samples were collected for $24 \mathrm{~h}$ by using the metabolic cages. The urinary protein level in the rats was quantified by a biochemical analyser (HITACHI 7180).

\section{Histological analysis}

A portion of kidney was fixed with $4 \%$ paraformaldehyde and embedded in paraffin. $3 \mu \mathrm{m}$-thick sections were cut and stained with haematoxylin and eosin (H\&E) and Masson's trichrome stain for examination of kidney histology. The degree of sclerosis in each glomerulus was subjectively graded on a scale of 0 to 4 as described previously [13]. The glomerular sclerosis index (GSI) was calculated by using the following formula as previously reported:

$\mathrm{GSI}=\frac{(1 \times \mathrm{N} 1)+(2 \times \mathrm{N} 2)+(3 \times \mathrm{N} 3)+(4 \times \mathrm{N} 4)}{\mathrm{N} 0+\mathrm{N} 1+\mathrm{N} 2+\mathrm{N} 3+\mathrm{N} 4}$, where $\mathrm{N}$ is the number of glomeruli at each grade of sclerosis.

\section{Transmission electron microscopy (TEM)}

After fixation in $2.5 \%$ glutaraldehyde overnight, the kidney tissue $\left(\sim 1 \mathrm{~mm}^{3}\right.$ in size) was rinsed in $0.1 \mathrm{M}$ PBS 
thrice. Then the specimens were post-fixed with $1 \%$ osmium tetroxide for $1 \mathrm{~h}$, dehydrated in graded series of acetone and embedded in graded Epon 812. Ultrathin sections $(80-100 \mathrm{~nm})$ were cut and stained with uranyl acetate (2\%) and lead citrate [15], and observed with a JEM-1400 transmission electron microscope (JEOL, Japan).

\section{Real-time quantitative PCR (qRT-PCR)}

Total RNA was isolated from kidneys of individual rats using the TRIzol reagent (Invitrogen, USA) and then cDNA was synthesized using a Primescript ${ }^{\mathrm{tm}} \mathrm{RT}$ reagent kit (TaKaRa, Japan) according to the manufacturer's instructions. Thereafter, expression levels of nephrin, podocin, and GAPDH were quantified via real-time PCR using Applied Biosystems 7500 Fast real-time PCR system (Thermo Fisher Scientific, USA). The sequences of primers used are shown in Table 1. Relative mRNA expression levels were normalized to those of GAPDH. Each PCR experiment was performed in triplicate and repeated independently at least thrice.

\section{Western blotting}

The rat kidney tissues were incubated with RIPA lysis buffer [20 mM Tris (pH 7.5), $150 \mathrm{mM} \mathrm{NaCl}, 1 \%$ Triton $\mathrm{X}-100,1 \%$ sodium deoxycholate, $0.1 \%$ SDS and $1 \mathrm{mM}$ EDTA] containing a proteinase inhibitor cocktail (Beyotime) at $4{ }^{\circ} \mathrm{C}$ for $30 \mathrm{~min}$. Cell lysates were centrifuged at $10,000 \mathrm{~g}$ for $10 \mathrm{~min}$ at $4{ }^{\circ} \mathrm{C}$. After quantification using the BCA assay, the protein extracts $(80 \mu \mathrm{g})$ were separated by $10 \%$ SDS-PAGE gels under reducing conditions. After the proteins were transferred onto a PVDF membrane, 5\% skimmed milk was used as the blocking agent, and then the membranes were next incubated with the primary antibodies. Antibodies used were as follows: anti-nephrin (Abcam, ab58968); anti-podocin (Abcam, ab93650); and anti-GAPDH (ProteinTech, 60,004-1-Ig). After hybridization, the blots were washed and incubated with infrared labelled anti-rabbit/mouse IgG Ab (1: 15000). Finally, the signal was detected using an Odyssey CLx image system (LI-COR).

Table 1 Primers used for gene expression analyses. F, forward primer; $\mathrm{R}$, reverse primer

\begin{tabular}{lll}
\hline Primer Name & Sequence $\left(5^{\prime}\right.$ to 3 $^{\prime}$ ) & Application \\
\hline Rat-nephrin-F & GTTGGTGGTCTTCTGCTGCTCTC & Real-time RT-PCR \\
Rat-nephrin-R & CTTCTGCTGTGCTAACCGTGGAG & Real-time RT-PCR \\
Rat-podocin-F & CCAGCAGCCACGGTAGTGAATG & Real-time RT-PCR \\
Rat-podocin-R & CCTCTGGTCGCTCGCTCTCC & Real-time RT-PCR \\
Rat-GAPDH-F & ACCACAGTCCATGCCATCAC & Real-time RT-PCR \\
Rat-GAPDH-R & TCCACCACCCTGTTGCTGTA & Real-time RT-PCR \\
\hline
\end{tabular}

\section{Statistical analysis}

Data are presented as means \pm SD values. The data shown were analysed for significance via Student's t-test or One-Way ANOVA using SPSS20.0 software (IBM Corporation, Armonk, NY, USA). A $p$-value less than 0.05 or 0.01 was considered statistically significance.

\section{Results}

\section{Effect of $P$. linteus decoction on urinary protein excretion} in FSGS rats

To establish a model for rat FSGS, we subjected rats to uninephrectomy followed by repeated injection of doxorubicin. The urinary protein levels for FSGS rats were significantly higher than that of control rats $(p<0.01$, Fig. 1a), indicating that the FSGS model had been successfully established. No rat mortalities were recorded during the course of the whole experiment. Besides, the serum albumin (ALB) level in the FSGS model decreased significantly compared with the control group $(p<0.01$, Fig. 1b). After the intervention with the $P$. linteus decoction, the $24 \mathrm{~h}$ urinary protein levels in PLD-LD and PLD-HD groups were much lower than that in the model group (Fig. 1a). Meanwhile, the ALB in the PLDLD group showed obvious improvement (Fig. 1b). No significant differences in the ALB levels between the model group and PLD-MD and PLD-HD group were observed. Collectively, these results indicate that the PLD-LD can attenuate urinary protein excretion and improve the serum ALB levels in the FSGS rat.

\section{Effect of $P$. linteus decoction on renal function in FSGS rats}

To further evaluate the effects of the $P$. linteus decoction on kidney function, the serum markers in different groups were measured. Serum creatinine ( $\mathrm{Scr}$ ), urea nitrogen (BUN), triglycerides (TG), and cholesterol (TC) were significantly increased in the FSGS group compared with the control group (Fig. 2). Additionally, the Scr, BUN, and TG were significantly reduced in the PLD-LD group compared with the model group. However, there were no significant differences in TC levels between the model group and the PLD-LD, PLD-MD and the PLD-HD groups (Fig. 2). These results are basically in line with the data from urinary protein, providing further evidence that PLD-LD could ameliorate kidney damage.

\section{Effect of $P$. linteus decoction on glomerular pathomorphology in FSGS rats}

The glomerular pathomorphology was further examined by histological analysis. H\&E and Masson's staining demonstrated that there was obvious focal glomerular sclerosis, interstitial lesions, and inflammatory cell infiltration in the model rats, whereas the control rats had no pathological changes (Fig. 3a). Furthermore, the GSI 

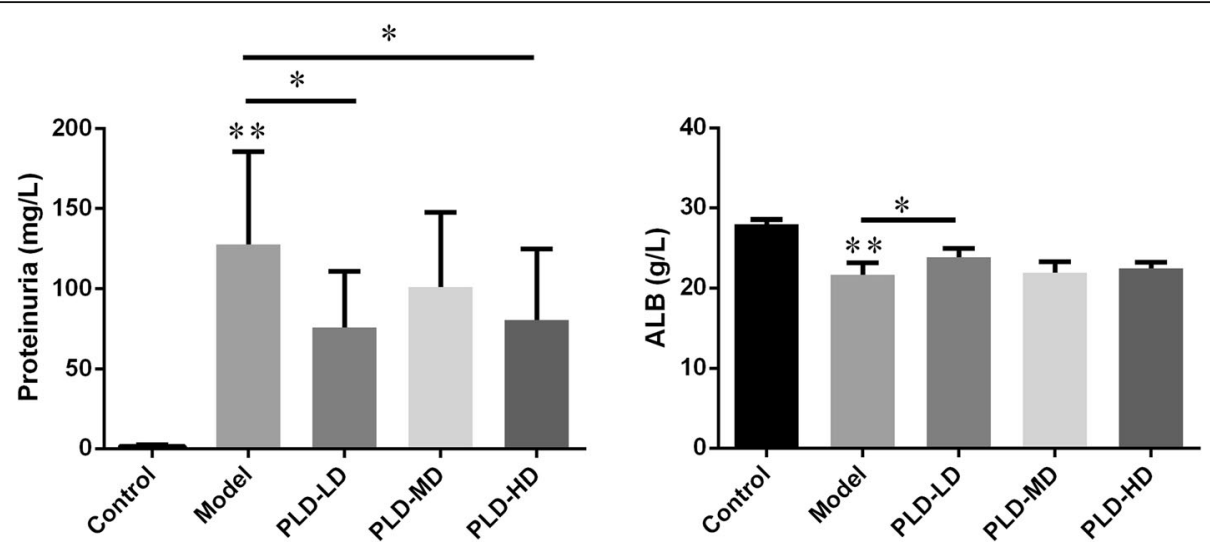

Fig. 1 Evaluation of proteinuria and serum ALB concentration. The $24 \mathrm{~h}$ urine and serum ALB concentrations were collected from experimental rats. Data $(n=6)$ are presented as the mean \pm SD. ${ }^{*} p<0.05 ;^{* *} p<0.01$

in the model group was much higher than that in the control group (Fig. 3b). After the P. linteus decoction intervention, such pathological damages were much improved compared with that in the model group, especially the PLD-LD group (Fig. 3a). Similarly, the GSI in the PLD-LD group decreased significantly compared to that in the model group (Fig. 3b).
Next, TEM was used to observe the degree of damage in the podocyte foot process. The results showed clear processes were observed on the surface of the glomerular epithelial cells in the control group (Fig. 4a). However, the foot processes diffusely effaced, became flat and fused and even disappeared in the model group. Compared with the control group, the foot process rate
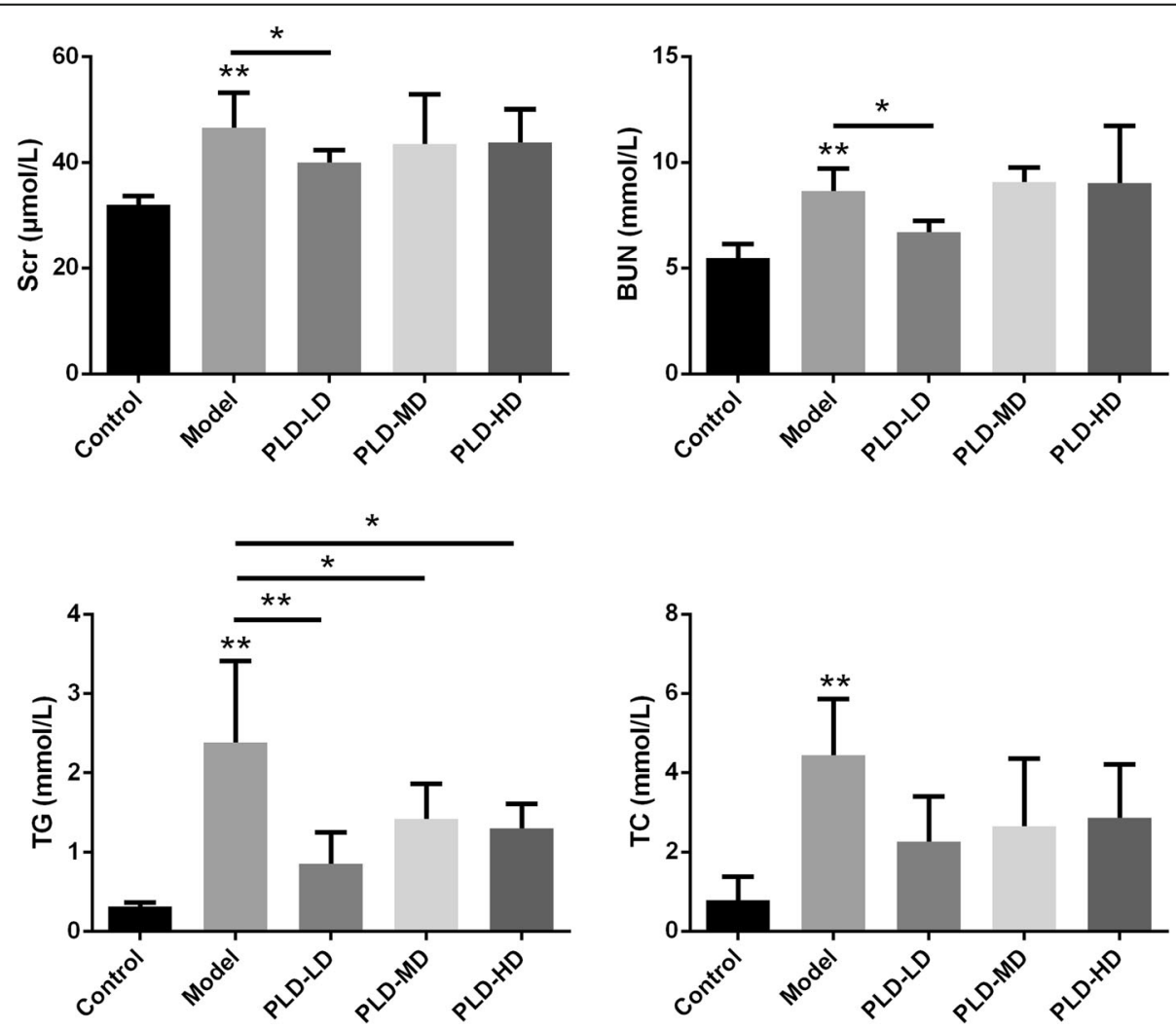

Fig. 2 Evaluation of renal function. The levels of Scr ( $\mu$ mol/L), BUN (mmol/L), TG (mmol/L), and TC (mmol/L) in serum from different groups of rats were determined by a chemical analszer (HITACHI 7180). Data $(n=6)$ are presented as the mean \pm SD. ${ }^{*} p<0.05 ;{ }^{* *} p<0.01$ 


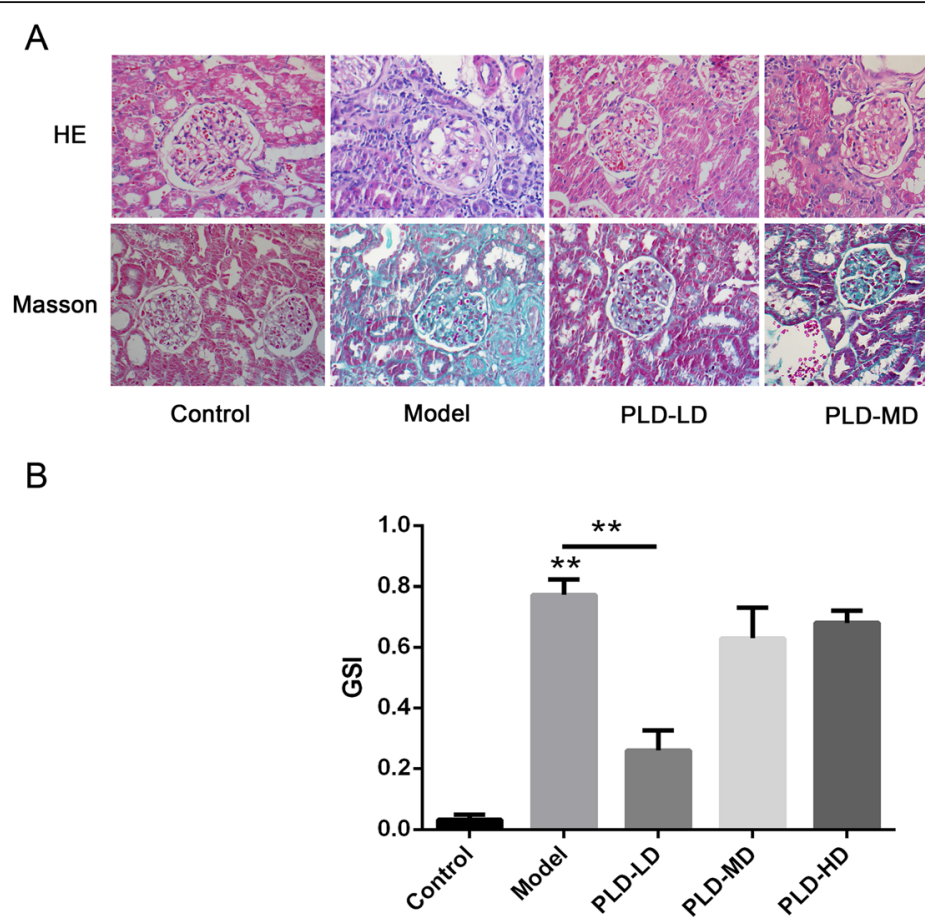

Fig. 3 Analysis of renal pathology by light microscopy. a Representative micrographs from each group are shown. The upper panel represents $\mathrm{H}$ \& E staining and the lower panel represents the Masson's staining (original magnification $\times 200$ ). $\mathbf{b}$ The GSI of each group. Data are presented as the mean \pm SD. ${ }^{*} p<0.05 ;{ }^{* *} p<0.01$

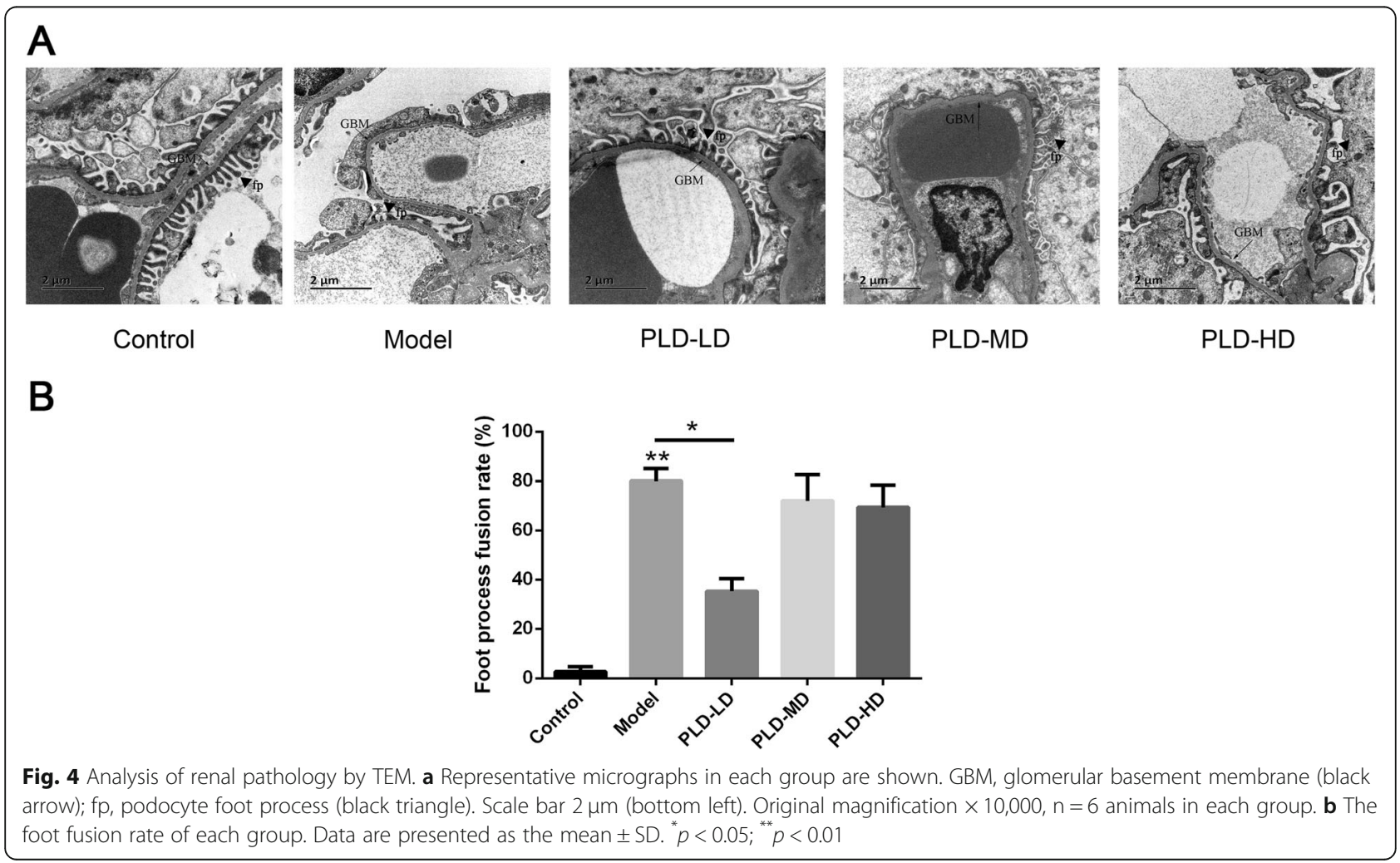


in the model group increased from $2.67 \pm 1.00$ to $80 \% \pm$ $6.12 \%$ (Fig. 4b, $p<0.01$ ). In the PLD-LD group, the lesions were significantly alleviated and foot fusion rate $(35.33 \% \pm$ 5.03\%) reduced compared with the model group. However, the lesions in PLD-MD and PLD-HD groups were much more serious than that in the PLD-LD group (Fig. 4a). Taken together, these results indicated that the PLD-LD treatment can alleviate the renal pathological damage.

\section{Effect of $P$. linteus decoction on renal nephrin and} podocin expression in FSGS rats

To further assess the effect of the P. linteus decoction on FSGS progression, the podocyte slit diaphragm proteins, nephrin and podocin were assessed. RT-PCR results showed the expression levels of nephrin and podocin were markedly decreased in the model group (Fig. 5a). In the PLD-LD intervention group, the expression of nephrin and podocin were increased significantly compared with that in the model group. However, there was no significant difference between the model and PLD-MD and PLD-HD groups (Fig. 5a). Similar results were observed by western blotting (Fig. 5b and c). These results suggested that PLD-LD can protect the podocyte slit diaphragm proteins nephrin and podocin.

\section{Discussion}

FSGS represents a major cause of the nephritic syndrome. It is the most common primary glomerular disorder causing ESRD. Hormones and immunosuppressants are the most extensively used agents in the treatment of FSGS. However, this therapeutic strategy is not considered ideal due to the occurrence of unpleasant side effects and steroid-resistance. Steroid-resistant patients with FSGS are of great concern to nephrologists as these patients are at significant risk for ongoing progression of ESRD.
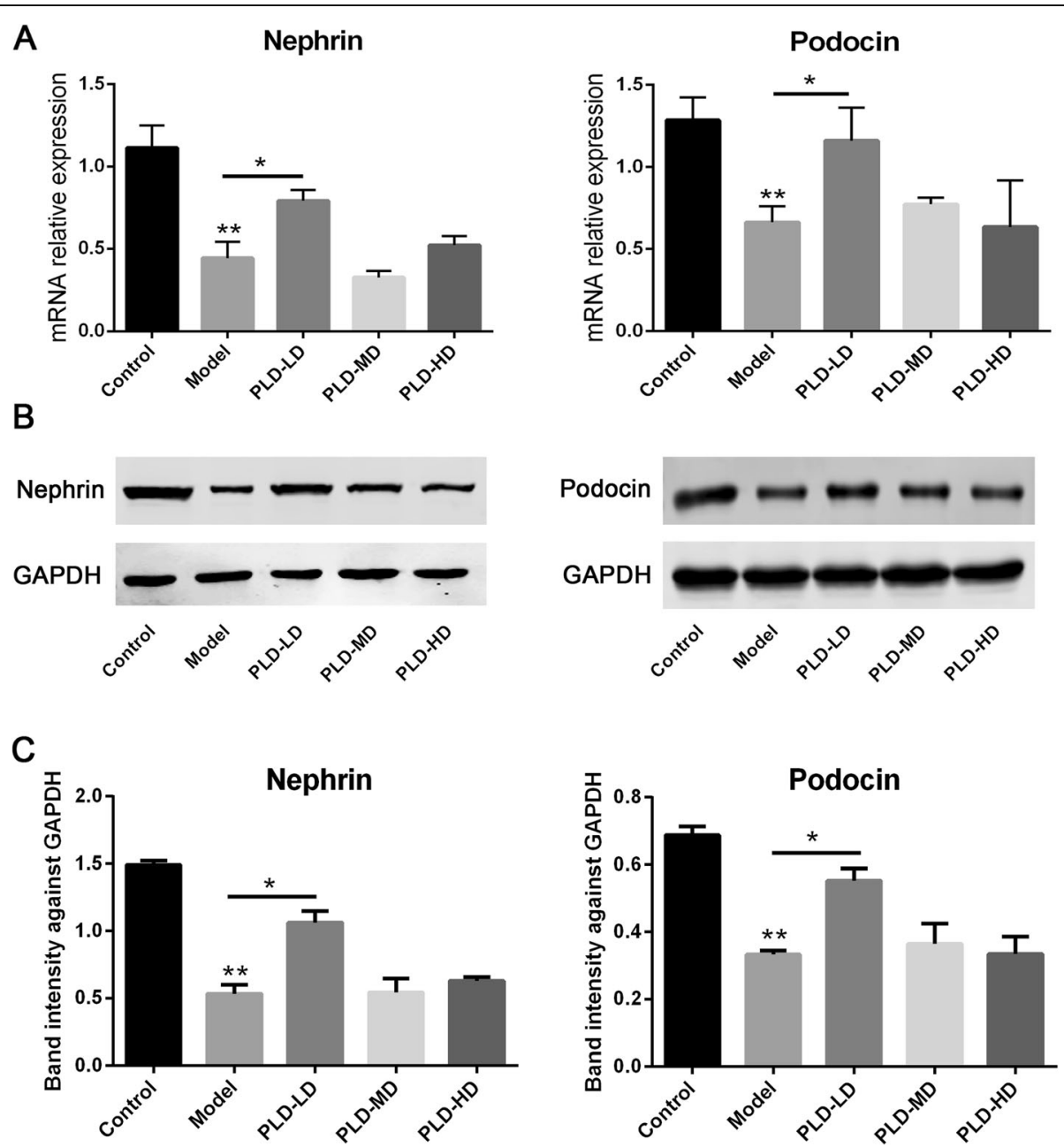

Fig. 5 Analysis of the expression of nephrin and podocin. a The mRNA expressions of nephrin and podocin in the rat kidney tissues were determined by qRT-PCR. The relative gene expression was normalized to that of GAPDH. Quantitative data are shown as the mean \pm SD. ${ }^{*} p<0.05$; ${ }^{* *} p<0.01$. b Representative western blot of nephrin and podocin in the rat kidney tissues. $\mathbf{c}$ Relative protein level was calculated by band intensity against GAPDH, respectively 
Therefore, there is an urgent need to seek a safer and more effective method to relieve FSGS progression.

$P$. linteus, a well-established medicinal mushroom, is also known as "forest gold". It has been used in Asian countries for centuries to prevent or treat diseases as diverse as haemorrhage, rheumatoid arthritis, gastroenteric dysfunction, diarrhoea, and cancers [16]. Recent studies have demonstrated that $P$. linteus has anti-hepatic fibrosis effect [10]. Considering its extensive biological role, $P$. linteus has become a hot research topic in the medical research, and has attracted much attention from scholars at home and abroad. Although the research on P. linteus includes many fields, until now, studies on its protective roles in chronic kidney disease have not been reported.

Podocyte, an important component of the glomerular filtration membrane, plays an important role in the development of FSGS [17]. Podocyte injury is a common feature of many glomerular diseases, which can lead to foot process fusion and cell detachment from the glomerular base membrane, thus resulting in proteinuria and glomerulosclerosis [18]. Nephrin is the main and the most abundant protein of the podocyte slit diaphragm (SD) [19]. Podocin is a membrane protein located exclusively in the SD region, with two intracellular domains that interact with nephrin. Changes in nephrin and podocin structures can lead to intense proteinuria [20,21]. In our study, PLD-LD partially reduced the fusion and effacement of the foot process, and increased nephrin and podocin expression, suggesting that podocyte injury is closely associated with the incidence of glomerular sclerosis in our model, and PLD-LD may attenuate the progression of FSGS through protection afforded to podocyte injury.

A potential limitation of our study was the failure to demonstrate a dose-dependent effect among PLD-LD, PLD-MD and PLD-HD groups. One possible explanation could be that the dose range we used was too high for rats. Therefore, further studies including much smaller doses are needed to ascertain the exact dose range and effect of $P$. linteus in FSGS rats.

In summary, this study revealed for the first time that $P$. linteus decoction can protect the podocyte injury in the kidney of FSGS rats. It is anticipated that this study can provide a theoretical basis for the application of $P$. linteus in the treatment of FSGS.

\section{Conclusions}

In conclusion, FSGS resembling primary FSGS in humans was established in rats by uninephrectomy and the repeated injection of doxorubicin. Then the effect of P.linteus decoction on FSGS rats was evaluated in this paper. After 12-week intervention with P.linteus decoction, urinary protein, Scr, BUN, TG and TC were significantly reduced in our experiment, especially in the PLD-LD group. The expression of renal nephrin and podocin were increased significantly. Moreover, the pathological damage in the renal tissue was also alleviated by the PLD-LD intervention. Taken together, the P. linteus decoction can alleviate the podocyte injury in the FSGS rat model, thus minimizing the progression of glomerular sclerosis and improving renal function.

\begin{abstract}
Abbreviations
FSGS: Focal and segmental glomerulosclerosis; GSI: Glomerular sclerosis index; HE: Haematoxylin and eosin; P. linteus: Phellinus linteus; PLD-HD: Highdose group of $P$. linteus decoction; PLD-LD: Low-dose group of $P$. linteus decoction ; PLD-MD: Medium-dose group of $P$. linteus decoction; Scr: Serum creatinine; BUN: urea nitrogen; SD: Podocyte slit diaphrag; TC: Cholesterol; TG: Triglycerides
\end{abstract}

\section{Acknowledgements}

Not applicable.

\section{Authors' contributions}

FW designed the study, conducted the animal experiments and drafted the manuscript. RCY was responsible for financial support of the study,

conceived and designed the study, and provided final supervision. YPS and YWT conducted animal experiment and gene expression. XLT performed the immunostaining and TEM. XLZ provided efforts in data analysis. YGL provided the $P$. linteus. YJW guided the whole experiment. All authors have approved the final version of the manuscript.

\section{Funding}

This work was funded by Key Research \& Development Program from Department of Science and Technology of Zhejiang Province (2018C02003) and National Natural Science Foundation of China (81803911). The funding bodies had no role in the design of the study and collection, analysis, interpretation of data and in writing the manuscript.

\section{Availability of data and materials}

The datasets used and analyzed during the current study are available from the corresponding author on reasonable request.

\section{Ethics approval and consent to participate}

The animal procedures were approved by the Animal experiment Ethics Committee of Zhejiang Institute of Traditional Chinese Medicine in

accordance with the principles outlined in the NIH Guide for the Care and Use of Laboratory Animals.

Consent for publication

Not applicable.

Competing interests

All authors declare that they have no competing interests.

\section{Author details}

${ }^{1}$ Department of Nephrology (Key laboratory of Zhejiang province, management of kidney disease), Guang Xing Hospital Affiliated to Zhejiang Chinese Medical University, Hangzhou 310007Tiyuchang Road 453People's Republic of China. ${ }^{2}$ Sericultural Research Institute, Zhejiang Academy of Agricultural Science, Hangzhou, China.

Received: 1 August 2019 Accepted: 9 October 2019

Published online: 21 October 2019

\section{References}

1. Zschiedrich S, Bork T, Liang W, Wanner N, Eulenbruch K, Munder S, Hartleben B, Kretz O, Gerber S, Simons M. Targeting mTOR Signaling Can Prevent the Progression of FSGS. J Am Soc Nephrol. 2017;28(7):2144-57 ASN.2016050519.

2. D'Agati VD, Fogo AB, Bruijn JA, J Charles J. Pathologic classification of focal segmental glomerulosclerosis: a working proposal. Am J Kidney Dis. 2004; 23(2):117-34. 
3. Séverine B, Hans-Kristian L, Michelle E, Erika NO, Bernard C, Antoine D. Optimal management of primary focal segmental glomerulosclerosis in adults. Int J Nephrol Renovasc Dis. 2017;10:97-107.

4. Yi L, Yuxia S, Chunling Z, Ke W, Peicheng S, Di H, Wen M, Jin Z, Lin L, Liqun H. Moxibustion Alleviates Injury in a Rat Focal Segmental Glomerulosclerosis Model. Evid Based Complement Altern Med. 2017;2017(4):7169547.

5. Li YG, Ji DF, Zhong S, Liu PG, Lv ZQ, Zhu JX, Chen JE, Chen HP. Polysaccharide from Phellinus linteus induces S-phase arrest in HepG2 cells by decreasing calreticulin expression and activating the P27kip1-cyclin a/ D1/E-CDK2 pathway. J Ethnopharmacol. 2013;150(1):187-95.

6. Zong $\mathrm{AZ}$, Cao HZ, Wang FS. Anticancer polysaccharides from natural resources: a review of recent research. Carbohydr Polym. 2012;90(4):1395-410.

7. Park BJ, Lim YS, Lee HJ, Eum WS, Park JS, Han KH, Choi SY, Lee KS. Antioxidative effects of Phellinus linteus and red ginseng extracts on oxidative stress-induced DNA damage. BMB Rep. 2009:42(8):500.

8. Kim BC, Jeon WK, Hong HY, Jeon KB, Lim CJ. The anti-inflammatory activity of Phellinus linteus (Berk. \& M.a. Curt.) is mediated through the PKCdelta/ Nrf2/ARE signaling to up-regulation of heme oxygenase-1. J Ethnopharmacol. 2007;113(2):240-7.

9. Zhao C, Liao ZS, Wu XQ, Liu YL, Liu XY, Lin ZX, Huang YF, Liu B. Isolation, purification, and structural features of a polysaccharide from Phellinus linteus and its hypoglycemic effect in Alloxan-induced diabetic mice. J Food Sci. 2014;79(5):H1002-10.

10. Wang HL, Wu G, Park HJ, Jiang PP, Sit WH, Griensven LJV, Wan JMF. Protective effect of Phellinus linteus polysaccharide extracts against thioacetamide-induced liver fibrosis in rats: a proteomics analysis. Chin Med. 2012;7(1):23

11. Wan F, Yang RC, Shi YP, Zhang HQ. Effect of different extracts from Phellinus Linteus on the TGF- $\beta 1$-induced epithelial-mesenchymal transition in rat renal tubular epithelial cells. Zhejiang Clin Med J. 2018;20(10):1637-9 (in Chinese).

12. Huang $Q$, Lin PH, Wang MA, Chen HQ, Zheng DD, Huang QH, Zhang SP, Shi ZL. Effect of Phellinus Linteus polysaccharide on the inhibition of renal interstitial fibrosis of diabetic mice through P311/TGF- $\beta 1 /$ Snail1 pathway. Pharmacol Clin Chinese Materia Medica. 2019;35(01):30-5 (in Chinese).

13. Yang $R C$, Zhu $X L$, Wang J, Wan F, Zhang HQ, Lin Y, Tang XL, Zhu B. Bone marrow mesenchymal stem cells attenuate the progression of focal segmental glomerulosclerosis in rat models. BMC Nephrology. 2018;19:335.

14. Ma HL, Wu YJ, Xu Y, Sun LP, Zhang XZ. Human umbilical Mesenchymal stem cells attenuate the progression of focal segmental Glomerulosclerosis. Am J Med Sci. 2013;346(6):486-93.

15. Birgit W, Melanie S, Wiebke S, Linda B, Brigitte P, Elina K, Ulrike B, Galuska $\mathrm{SP}$, Hildegard $\mathrm{G}$, Rudolf $\mathrm{G}$. Deficits in sialylation impair podocyte maturation. J Am Soc Nephrol. 2012;23(8):1319.

16. Zhu T, Kim SH, Chen CY. A Medicinal Mushroom: Phellinus Linteus. Curr Med Chem. 2008;15(13):1330-5.

17. Wen Y, Shah S, Campbell KN. Molecular mechanisms of proteinuria in focal segmental Glomerulosclerosis. Front Med. 2018;5:98.

18. Yu H. Genetic and cellular studies of the Podocyte in focal segmental Glomerulosclerosis. In: Dissertations \& Theses - Gradworks; 2015.

19. Verma R, Venkatareddy M, Kalinowski A, Li T, Kukla J, Mollin A, Carafuentes G, Patel SR, Garg P. Nephrin is necessary for podocyte recovery following injury in an adult mature glomerulus. PLoS One. 2018;13(6):e0198013.

20. Huber T. Interaction with podocin facilitates nephrin signaling. J Biol Chem. 2001;276(45):41543-6.

21. Saleem MA, Lan N, lan W, Karl T, Vesa R, Peter M, Peter WM. Co-localization of Nephrin, Podocin, and the actin cytoskeleton: evidence for a role in Podocyte foot process formation. Am J Pathol. 2002;161(4):1459-66.

\section{Publisher's Note}

Springer Nature remains neutral with regard to jurisdictional claims in published maps and institutional affiliations.

Ready to submit your research? Choose BMC and benefit from:

- fast, convenient online submission

- thorough peer review by experienced researchers in your field

- rapid publication on acceptance

- support for research data, including large and complex data types

- gold Open Access which fosters wider collaboration and increased citations

- maximum visibility for your research: over $100 \mathrm{M}$ website views per year

At BMC, research is always in progress.

Learn more biomedcentral.com/submissions 